\title{
A Study on the Relationship between Social Policy and Social Capital: Evidence from Asian Countries
}

\author{
Yung Soo Lee ${ }^{1}$ \\ ${ }^{1}$ Department of Social Welfare, Incheon National University, Incheon, Republic of Korea \\ Correspondence: Yung Soo Lee, Department of Social Welfare, Incheon Natioinal University, 119 Academy-ro, \\ Yeonsu-gu, Incheon, 22012, Republic of Korea. Tel: 82-032-835-8319. E-mail: ylee1026@ gmail.com
}

Received: April 2, 2020

doi:10.5539/ass.v16n5p96
Accepted: April 20, 2020

Online Published: April 30, 2020

URL: https://doi.org/10.5539/ass.v16n5p96

\begin{abstract}
There are two competing hypotheses regarding the relationship between social policy and social capital. The crowding-out hypothesis suggests that public resources allocated through social policies and programs eradicate various forms of social capital such as trust, social network and norms. The crowding-in hypothesis, on the contrary, emphasizes virtuous cycles between social policy and social capital. Empirical evidence, mostly conducted for Western countries with advanced economies, has not produced consistent findings regarding the relationship. This study empirically tested these hypotheses based on data from 24 Asian countries. This study further explored how relationships between social policy and social capital vary by sub-regions of Asian countries. Findings from both macro- and micro-level analysis suggest that social policy influences social capital differently according to the forms of social capital. There also seems to be heterogeneity across sub-regions in the relationship between social policy and social capital. Theoretical and policy implications as well as future research directions were further discussed.
\end{abstract}

Keywords: social capital, social welfare policy, crowding-out, crowding-in, World Value Survey

\section{Introduction}

One of the most crucial and at the same time complex issues in the literature on social capital is the relationship between social policy and social capital. There are two competing hypotheses regarding this relationship: the crowding-out and crowding-in hypothesis. The crowding-out hypothesis holds that allocations of public resources through various measures of social policies and programs displace social capital. More specifically, social policies and programs, or in a broader term welfare states, crowd out various forms of social capital such as social network and reciprocity, which in turn leads to a decline of civil norms, participation in civil society, and trust in fellow citizens and social institutions (Ferragina, 2017; Fukuyama, 2000; Putnam, 2000; van Oorschot \& Arts, 2005). The crowding-in hypothesis, on the contrary, asserts that generous welfare state enhances accumulation of social capital. Well-designed welfare state can be a solid basis for developing civil societies. Universal social policies based on principles of equal treatment enhance generalized trust among individuals (Rothstein \& Uslander, 2005). Welfare state also can exert a positive influence on other forms of social capital by investing in voluntary organizations, providing time and resources to develop social capital, and setting the conditions for solidarity (van Oorschot \& Arts, 2005).

As discussed in depth below, an increasing number of research has been conducted to empirically test these two seemingly contradictory hypotheses; yet, empirical evidence has not produced consistent findings. Moreover, existing studies have examined the relationship between social policy and social capital mostly for Western countries with advanced economies. Empirical evidence is still needed, especially for developing or less developed countries. To fill the gap in the current literature, this study explored how social policy is associated with various forms of social capital explicitly focusing on Asian countries with different economic, social, political, and cultural contexts, and compared findings with those from Western counterparts. Further, heterogeneity among sub-regions of Asian countries is considered by analyzing how the relationship between social policy and social capital differ by sub-regions. 


\section{Literature Reivew}

\subsection{Concept of Social Capital}

Although considerable theoretical and empirical research on social capital has been conducted across a wide range of disciplines in social science, there seems to be no simple, unified definition of social capital. This may reflect highly theoretical, intangible as well as complicated aspects of social capital.

Bourdieu defined social capital as "the aggregate of the actual or potential resources which are linked to possession of a durable network of more or less institutionalized relationship (Bourdieu, 1985, p. 248)." American sociologist Coleman defined social capital by its function; that is, social capital is not a single entity and has at least two elements in common: social structure and actions of actors within the structure (Coleman, 1988). While theoretical roots differ between the two renowned scholars, they share common features that social capital is a set of social resources inherent in the relationship between actors or among actors. Coleman (1988) further suggested three forms of social capital: the level of trust evidenced by obligations and expectations, the information available from social networks and relations, and the norms and sanctions that promote the common good over self-interest.

For Putnam (1995, 2000), social capital refers to connections among individuals including social networks and norms of reciprocity as well as trustworthiness arising from them which facilitate coordination and cooperation for mutual benefit. Similarly, OECD (2001) defined social capital as a network with shared norms, values and understanding facilitating cooperation within or among groups.

Rothstein and Uslander (2005) further distinguished generalized trust from particularized trust. According to them, generalized trust means trust between people with different attributes and it reflects bonds across varying economic, ethnic, religious and racial groups. Particularized trust is an in-group faith reflecting social strains where each group in a society looks out for its own interests. Other scholars classified social capital into three types: bonding, bridging, and linking social capital (Healy, 2002; Woolcock, 2001). Bonding social capital means ties and networks among homogeneous groups characterized by dense and high levels of inter-personal trust. Bridging social capital refers to social ties across diverse, heterogeneous groups. Linking social capital refers to ties and networks within a hierarchy based on differences in social position or power (Woolcock, 2001).

As briefly discussed so far, social capital is a multi-faceted, multi-dimensional concept and there is no unified definition every scholar agreed upon. However, common elements can be found: generalized trust, social network, and social norms. The current study used these three forms as measures of social capital for the subsequent empirical analyses. More details on social capital measures were discussed in the method section below.

\subsection{Crowding-out versus Crowding-in Hypothesis}

There are two competing hypotheses with regard to the relationship between social policy (or in a broader term, welfare states) and social capital: the crowding-out and crowding-in hypothesis.

The crowding-out hypothesis holds that generous, comprehensive social policies and programs crowd out social networks and reciprocity, which leads to a decline of commitment to civil norms, participation in civil society, and trust in fellow citizens and institutions (Fukuyama, 2000; Putnam, 2000; van Oorschot \& Arts, 2005). The crowding-out hypothesis can be explained at least in two ways. First, substitution arugment suggests that welfare state takes over functions of civil society (Finsveen \& van Oorschot, 2007). Government activities and generous benefits through social policies and programs may make people less dependent on networks, which in turn leads to less investment in those networks (Scheepers, Grotenhuis, \& Gelissen, 2002). Welfare state can also have a detrimental effect on civic engagement such as volunteering and membership in organizations by taking over service production functions in private sectors. Second, passivity argument asserts that, if welfare state is too "big", people are more likely to be dependent on the state programs and benefits, which might result in weaker ability to organize those activities themselves (Finsveen \& van Oorschot, 2007; Fukuyama, 1999). In the same vein, state driven activities as well as excessive coverage against social risks realized by the large welfare state may rule out private control and create dependencies among individuals. These all could result in less social trust and norms, and substitution of bureaucratic ties for voluntary activities in the private sectors (Ferragina, 2017). Large welfare states could also make voluntary reciprocity harder to create since strong reciprocal ties and civic engagement may be substituted for a broader systems of social policies and programs (Kumlin \& Rothstein, 2005).

The crowding-in hypothesis argues that generous social policies and programs enhance trust, social network, and other forms of social capital. Scholars upholding this argument focus on the Scandinavian welfare states where a 
high level of social capital and generous welfare states seem to co-exist. The crowding-in hypothesis concludes that specific designs of welfare state matters in terms of making or breaking social capital. More specifically, welfare states with universal social policies and programs enhance the sense of generalized trust and social norms among citizens; on the contrary, welfare states with selective, means-tested type social policies may deepen class or racial division within society leading to less generalized trust and social norms (Ferragina, 2017; Kumlin \& Rothtein, 2005; Rothtein, 2001; Rothtein \& Uslander, 2005). Well-designed welfare state creates conditions for a thriving civil society by investing more in voluntary organizations as well as providing resources and time to develop social capital (van Oorschot \& Arts, 2005). Skocpol (1996) also emphasized that the historical importance of the state in generating trust and reciprocity in the United States. According to her, in the United State, civic engagement has been historically supported in partnership with the state.

Rostein and Uslander (2005) further suggested causal mechanisms through which social policy exerts an influence on social capital. That is, generous social policies lessen economic inequalities, and lowered inequalities are positively associated with higher social capital.

Considerable research has been conducted to empirically test the relationship between social policy and social capital, and these studies do not reach consistent conclusions. Arts and his colleagues (2003) tested the relationship between welfare regimes and social capital, and the findings confirmed that the Scandinavian welfare states had highest social capital, and the opposite was true for the Mediterranean welfare states as argued by the crowding-in hypothesis. In the same vein, Kaariainen and Lehtonen (2006) examined how welfare state regimes are related to formation of different forms of social capital based on the data from 21 countries. Main independent and dependent variables included five types of welfare state regimes and four different forms of social capital. The authors concluded that the crowding-in or institution-centered hypothesis was supported. They also found evidence that the relationships vary by different forms of social capital.

Hagfors and Kajanoja (2007) empirically examined interdependences between different forms of social capital and various aspects of the welfare state. Macro-level analysis based on 23 advanced countries showed that higher levels of social expenditure and decommodification of the welfare states were associated with lower income inequalities, higher generational income mobilities, and higher levels of individuals' freedom of choices, all of which resulted in higher generalized trust and bridging social capital. Tamilina (2009) also empirically investigated the impact of welfare state on social trust formation based on the cross-sectional data from 18 OECD countries. She employed the concept of decommodification and stratification developed by Esping-Andersen (1990) as measures of the welfare state. Findings indicated that decommodification enhances social trust mainly via lowered income inequality. Forms of stratification also mattered in terms of social trust. For example, universal approaches in Scandinavian countries were associated with higher social trust. Preserving existing class structures in the Conservative welfare regime was negatively associated with institutional trust; however, the opposite was true for interpersonal trust. Stigmatizing approaches in the Liberal welfare state regime were found to erode interpersonal trust, but boost institutional trust.

van Oorschot and Arts (2005) tested the crowding-out hypothesis using the data from the European Value Survey 1999/2000 for 23 European countries. No significant relationship between the welfare state and social capital was found at the country-level, aggregate analyses. At individual-level analyses, types and sizes of the welfare state were found to matter for the accumulation of social capital, but this hold only for generalized trust. More recently, Brewer, Oh, and Sharma (2014) investigated the effect of total social expenditure on social trust among 18 OECD countries. Findings from fixed effects analyses supported positive relationships between the two. Further tests on the potential reverse causality suggested that causality is from social expenditure to trust as hypothesized. Ferragina (2017) also empirically explored the relationship between welfare states and social capital among European countries over two decades. Findings suggested that the size of the welfare state measured by levels of social expenditure was negatively associated with various dimensions of social capital such as trust, social network, and social norms. However, the generosity of the welfare state measured by decommodification was positively related to social capital.

Visser and his colleaugues (2018) examined how total and various types of social spending influence informal social capital. Multilevel logistic regression based on the European Social Survey showed that social spending was positively associated with informal social capital. However, if unobserved heterogeneity across countries was controlled, significant relationships disappeared. Overall, the crowding-in hypothesis was supported for the informal dimension of social capital.

Bartel and his colleagues (2011) examined how public spending affects volunteering based on both quantitative and qualitative approaches using two sets of the British survey data. Findings suggested that volunteering 
declined as government intervention decreased, contradicting the crowding-out hypothesis. Government spending might crowd out volunteering and philanthropic donations, but the negative effect was relatively small. Based on exhaustive review of the literature, Bredtmann (2016) concluded that there were relatively small or incomplete effects of public spending on volunteering and donations. There is evidence that people in countries with high social spending were more likely to participate in philanthropic donations (Wit, Meumayr, Handy, \& Wiepking, 2018).

\section{Method}

\subsection{Data}

This study utilized both macro- and micro-level data for 24 Asian countries. Data on social capital measures and individual-level covariates were derived from the World Value Survey (WVS) wave 6. The WVS includes nationally representative survey data for over 100 participating countries. The WVS wave 6 data were collected between 2010 and 2014 for parcipating countries. Since the current study focuses on Asian countries, 24 Asian countries were included in the subsequent analyses. Those countries include Armenia, Azerbaijan, China, Cyprus, Georgia, Hong Kong, India, Japan, Jordan, Kazakhstan, Kuwait, Kyrqyzstan, Lebanon, Libya, Malaysia, Parkistan, Philippines, Quartar, Singapore, South Korea, Taiwan, Thailand, Turkey, and Uzbekistan.

Country-level data on social expenditure, the main independent variable, were derived from the World Social Protection Report published by International Labour Organization (ILO, 2017). Both macro- and micro-level data were pooled together and used for analyses.

\subsection{Measures}

The main dependent variables of this study include three forms of social capital as discussed earlier: generalized trust, social networks, and social norms. Generalized trust was measured by the WVS survey question: "Generally speaking, would you say that most people can be trusted or that you need to be very careful in dealing with people?" Those who answered that most people can be trusted were coded as 1 and those answered they need to be careful were coded as 0 . Social networks were measured based on the WVS questioinnaires on memberships in various voluntary organizations such as church or religious organization, sport or recreational organization, political party, humanitarian or charitable organization, and others. Active and inactive members for each organization were coded as 2 and 1, respectively; those with no membership were coded as 0 . These scores were summed across questionnaires. Social norms were also measured by five survey questions from the WVS, "Claiming government benefits to which you are not entitled," "Avoiding a fare on public transport," "Stealing property," "Cheating on taxes if you have a chance," "Someone accepting a bribe in the course of their duties" Response categories were based on a 10-point likert scale with higher numbers denoting more "justifiable". In the country-level, aggregate analysis, average scores of these three social capital measures were calculated for each country.

Next, individual-level covariates from the WVS included gender, age, social class, income scale, employment status, education, marital status, and having a child. Gender was a dichotomous measure ( $1=$ female, $0=$ male). Age was a continuous measure. Social class was originally a 5-level ordinal measure (1=upper class, $2=$ upper middle class, $3=$ lower middle class, $4=$ working class, $5=$ lower class), and reverse-coded so that higher scores indicate higher social classes. Income scale was measured based on a 10-point likert scale with higher numbers indicating higher income groups. Employment status was reorganized into a 5-level categorical variable (1=full-time, 2=part-time, 3=self-employed, 4=unemployed, 5=not working). Education has 9 response categories, and was treated as a continuous measure with higher numbers denoting higher levels of education. Marital status was reorganized into a 3-level categorical variable ( $1=$ married, $2=$ divorced/separated/widowed, $3=$ single). Having a child was a dichotomous measure ( $1=$ yes, $0=$ no).

Turning to country-level measures, social expenditure, derived from the ILO (2007), was measured as \% of GDP. In the ILO measure of social expenditure, a wide range of institutions were covered including, but not limited to, social insurance scheme, universal non-contributory scheme, provident funds, social schemes for public employees, employment injury schemes, family benefit schemes, unemployment schemes, industrial and occupational schemes, public social assistance, and national health services (ILO, 2007). A series of dummy-variables representing sub-regions of Asian countries were also included in the analytic model where necessary.

\subsection{Statistical Procedures}

This study empirically examined the relationship between social policy and social capital using both macro- and micro-level data. For the country-level, aggregate analyses, simple bivariate regression analyses were conducted 
using country-level measures of social capital and social expenditure.

For the main regeression analysis, individual-level social capital meausres were regressed on country-level social expenditure as well as other individual-level covariates. Since the analysis utilized individual-level survey data pooled across 24 Asian countries, individuals are clustered within countries. If igonored, standard errors might be under-estimated (Wooldridge, 2002). Considering these concerns, results using cluster-robust standard errors were presented. Next, to further explore how the relatioinships between social expenditure and social capital varies by sub-regions of Asian countries, a series of dummy variales representing each sub-region as well as interaction-terms between regional dummies and social expenditure were added to the analytic model.

\section{Results}

\subsection{The Relationship between Social Policy and Social Capital: Aggregate-level Analysis}

Aggregate-level relationships between social expenditure and each of three forms of social capital were depicted in Figure 1, 2, and 3, respectively. A linear regression line based on plots as well as 95\% of confidence intervals, shadow areas around the linear regression line, were also presented.

Figure 1 presents the relationship between social expenditure and generalized trust. There does not seem to be a significant association between social expenditure and generalized trust $(\mathrm{r}=0.03, \mathrm{p}=0.89)$. If we look further into the plots, countries such as Hong Kong, Singapore, and Thailand were characterized by low levels of social expenditure and relatively moderate to high levels of generalized trust. Philippines, Malaysia, Lebanon and India showed low levels in both social expenditure and generalized trust. Countries with relatively moderate to high levels of social expenditure and low levels of generalized trust included Uzbekistan, Turkey, Jordan, and Georgia. Both social expenditure and generalized trust were relatively high in China, Kazakhstan, Kyrgyzstan, South Korea, and Taiwan. Japan and Cyprus seem to be outliers. Both Japan and Cyprus showed highest levels of social expenditure among the study countries, but levels of generalized trust were moderate to high for japan, and quite low for Cyprus.

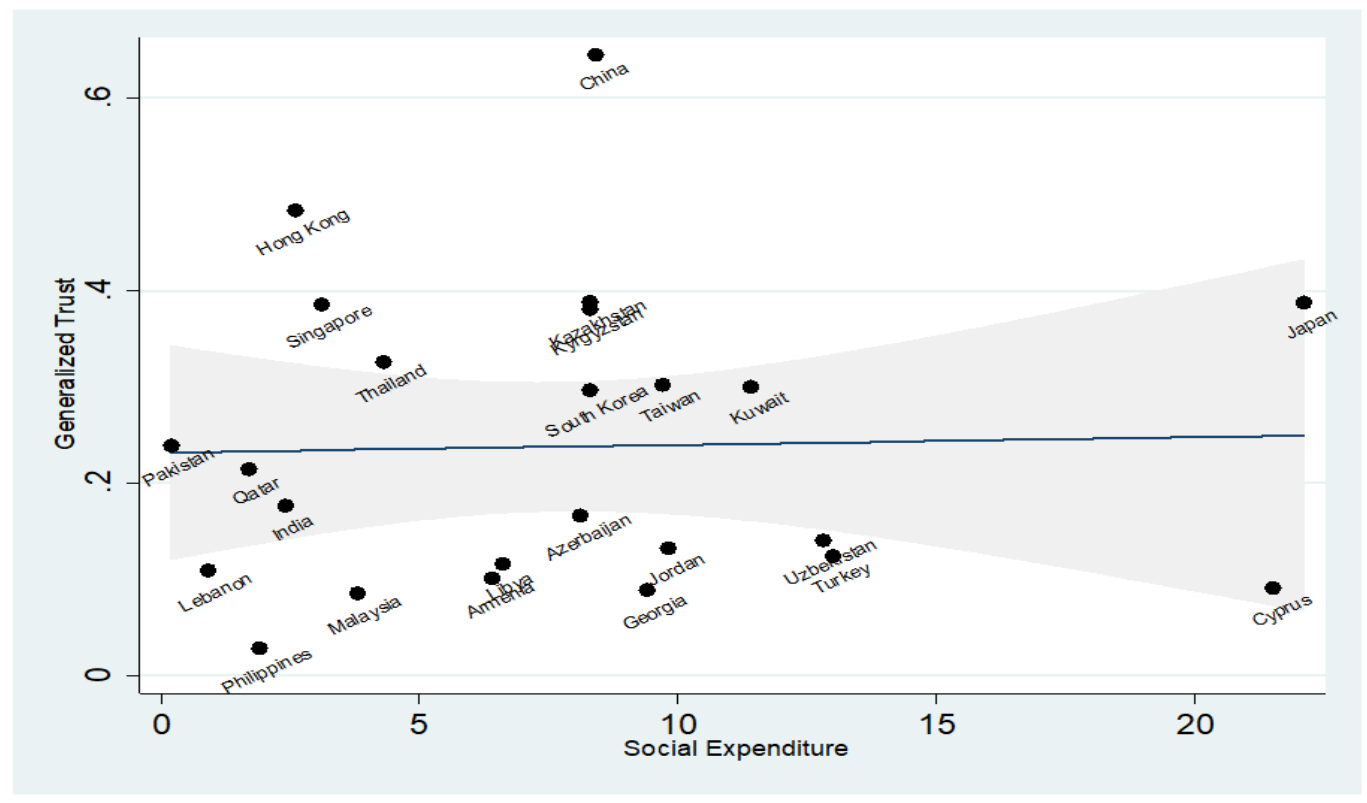

Figure 1. Social Expenditure and Generalized Trust

Figure 2 presents the relationship between social expenditure and social networks. Social expenditure and social networks seemed to be negatively associated, but the relationship was not statistically significant as well $(\mathrm{r}=-0.30, \mathrm{p}=0.16)$. Plots in Figure 2 showed that countries such as Philippines, Hong Kong, India, and Thailand were characterized by low levels of social expenditure and relatively high levels of social networks. Although generalized trust was relative low in Philippines and India as depicted in Figure 1, levels of social networks were higher, compared to other countries. Countries such as Parkistan had low levels of both social expenditure and social networks. Taiwan was a country with moderate to high social expenditure and highest levels of social networks; however, many other countries with similar levels of social expenditure showed relatively low levels of social networks. Cyprus and Japan with highest levels of social expenditure were more closely clustered in terms of social networks compared to generalized trust. 


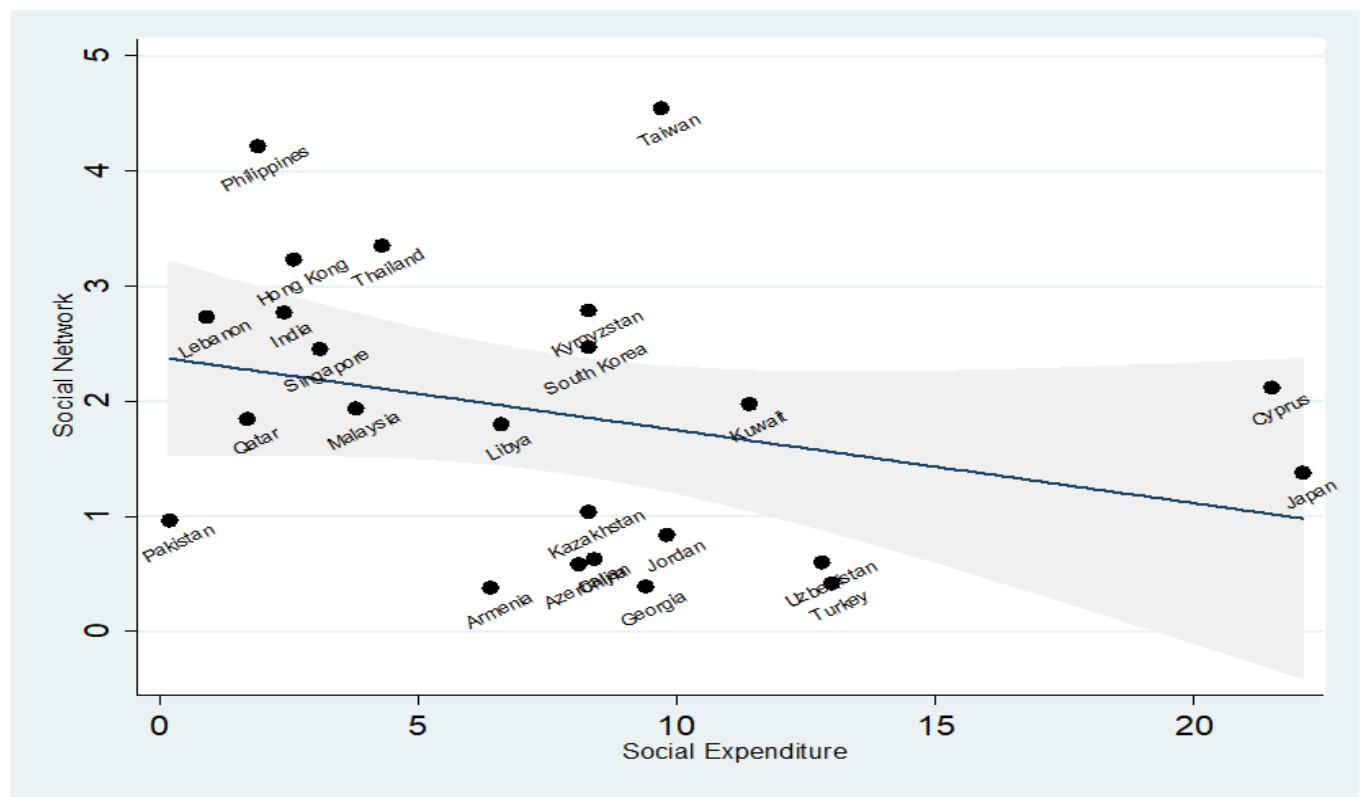

Figure 2. Social Expenditure and Social Networks

Figure 3 depicts the relationship between social expenditure and social norms among 24 Asian countries. Social expenditure and social norms were negatively associated, and the relationship was statistically significant $(\mathrm{r}=-0.47, \mathrm{p}=0.02)$. Since higher scores in social norms indicate lower social norms as discussed in the measurement section, this result indicates that countries with higher levels of social expenditure tend to have higher social norms. Looking further into the plots, countries such as Philippines, Lebanon, Hong Kong, and Singapore were clustered around low levels in both social expenditure and social norms. On the contrary, Japan and Cyprus showed high levels of both social expenditure and social norms.

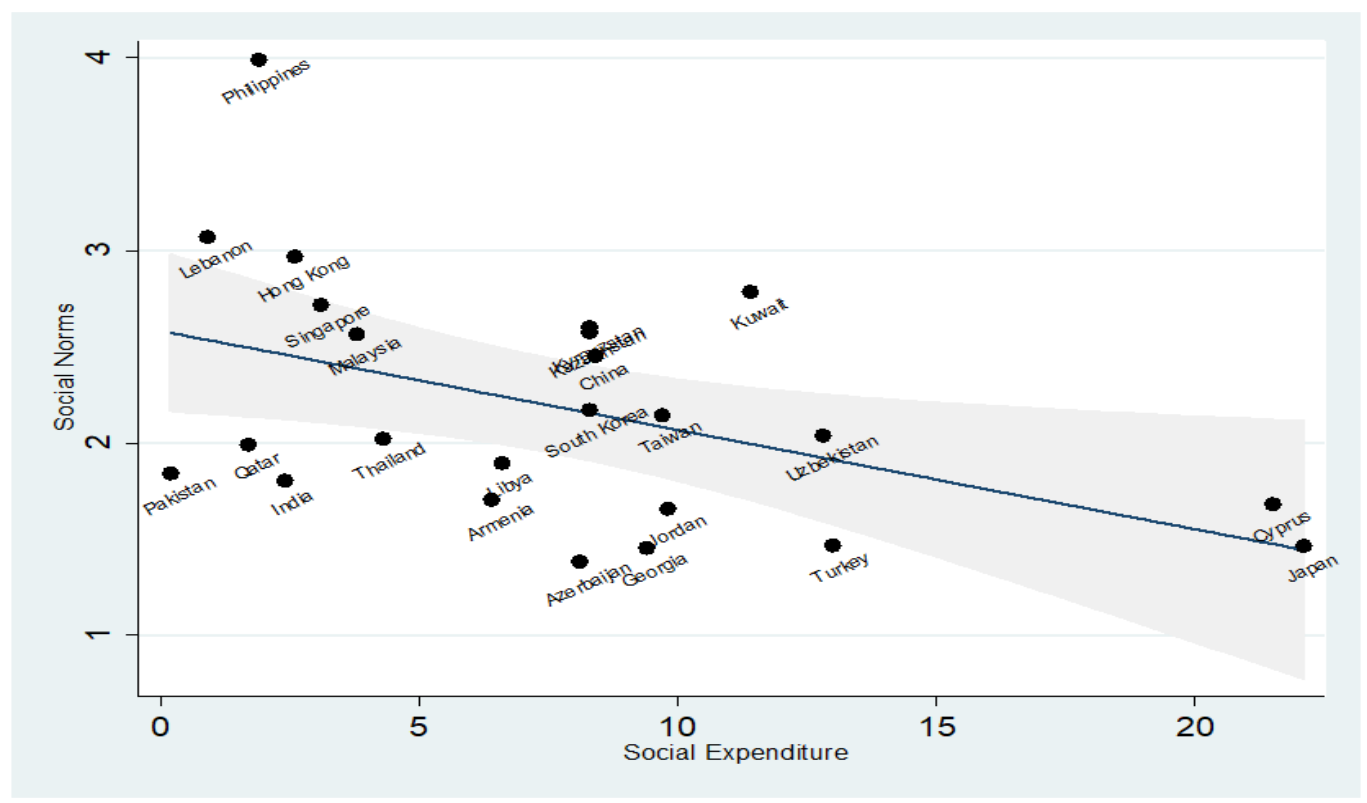

Figure 3. Social Expenditure and Social Norms

In sum, simple bivariate regression analysis based on country-level data showed that associations between social expenditure and social capital vary depending on forms of social capital. Social expenditure was significantly associated with only one of the three social capital indicators, social norms.

\subsection{The Effect of Social Policy on Social Capital: Multivariate Regression Analysis}

Findings from multivariate regression analyses are presented in Table 1. As discussed earlier, the main dependent variables include three individual-level social capital measures: generalized trust, social networks, and social norms. Independent and control variables include both individual- and country-level measures. Considering 
hierarchical structures of the data (e.g., individuals clustered within countries), cluster-robust standard errors were utilized.

According to Table 1, there was no statistically significant relationship between social expenditure and generalized trust after controlling for individual level covriates such as age, gender, social class, income, employment status, education and so on. However, there were statistically significant associations between social expenditure and other two forms of social capital, social networks and social norms. Individuals in countries with higher social expenditure seemed to have lower social networks and higher social norms.

Turning to the findings for individual-level covriates, age and employment status were significantly associated with generalized trust. That is, as individuals get older, they are more likely to have higher generalized trust. In terms of employment status, unemployed persons had lower generalized trust compared to full-time workers. Gender, social class, and employment status were significant predictors of social networks. Socal networks were lower for women compared to men, and individuals with higher social classes tended to have higher social networks. Non-employed persons showed lower social networks compared to full-time workers. Last, employment status and marital status were significantly associated with social norms. More specifically, social norms were higher for married persons compared to the non-married.

Table 1. Relationships between social expenditure and social capital: Multivairate regression analysis

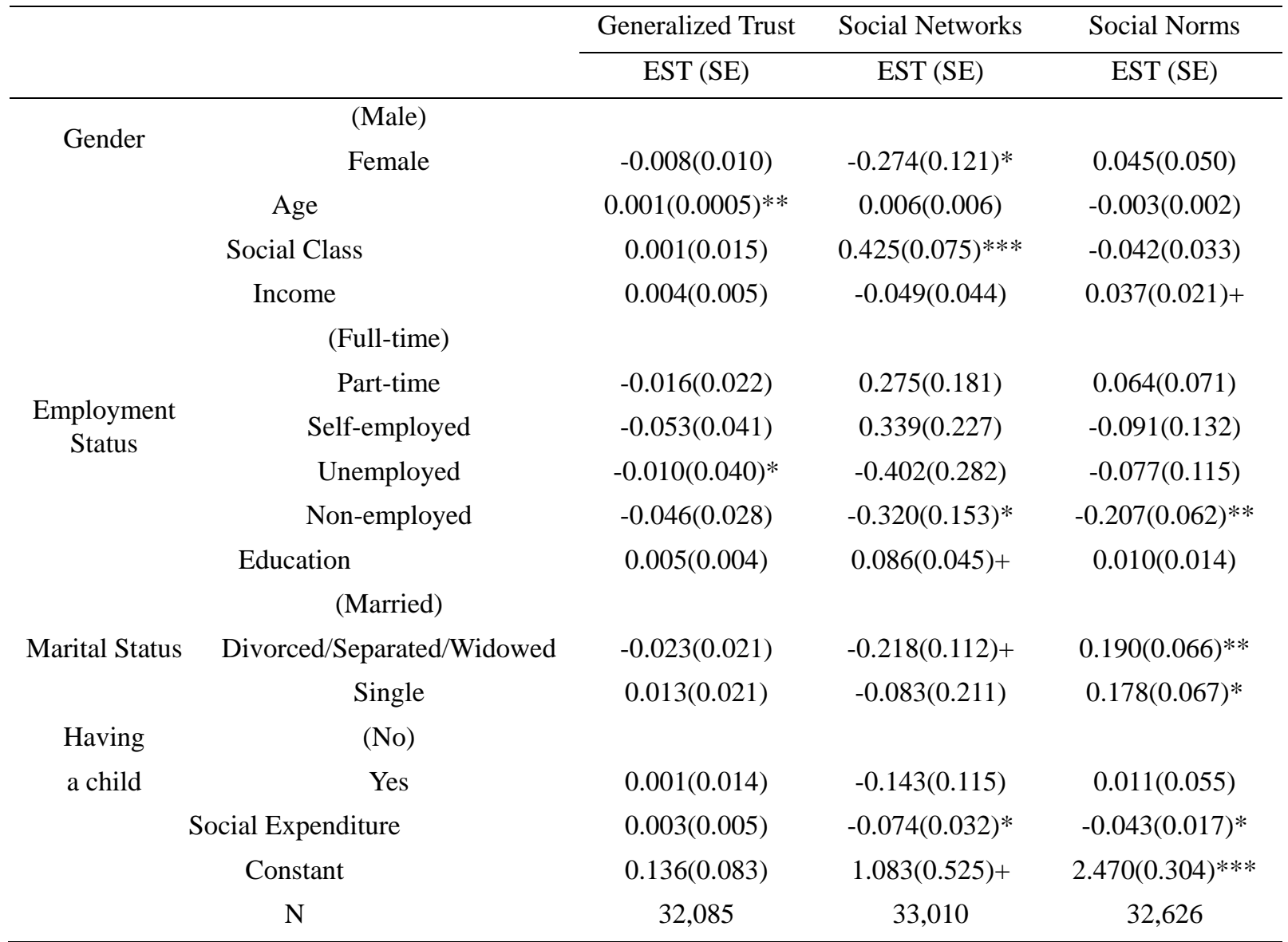

Note. Standard errors were calculated using cluster-robust standard errors. $+\mathrm{p}<.10,{ }^{*} \mathrm{p}<.05,{ }^{* *} \mathrm{p}<.01,{ }^{*} * * \mathrm{p}<.001$

\subsection{Heterogeniety in the Relationship between Social Policy and Social Capital across Sub-regions}

Next, to further explore how the relationship between social policy and social capital varies by sub-regions of Asian countries, a series of dummy variables indicating each sub-region as well as interaction terms between regional dummies and social expenditure were added to the analytic model. Findings presented in Table 2 clearly show that there is substantial heterogeneity across sub-regions in terms of the relationship between social expenditure and social capital. 
Table 2. Relationships between social expenditure and social capital by sub-regions

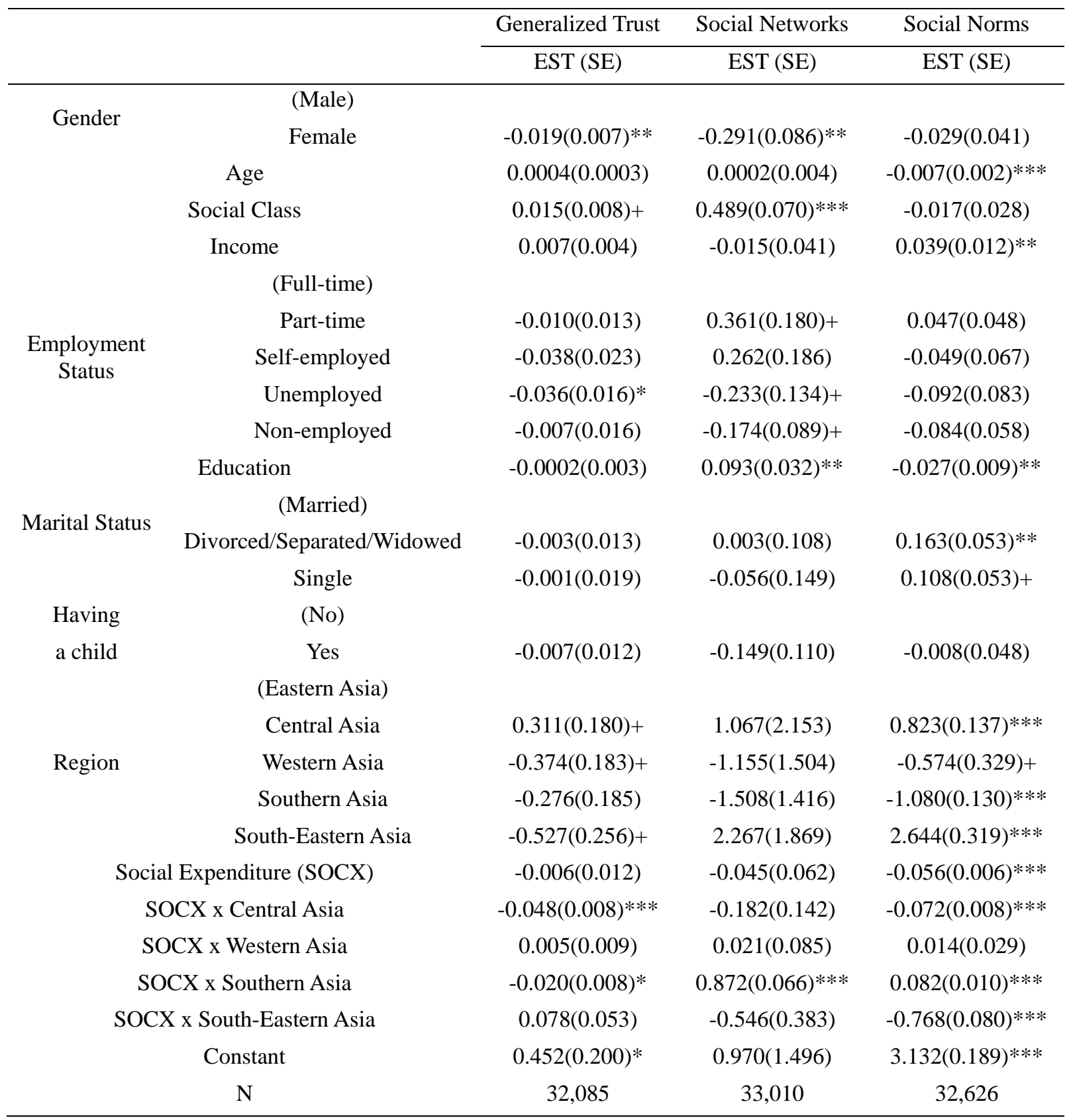

Note. Standard errors were calculated using cluster-robust standard errors. $+\mathrm{p}<.10, * \mathrm{p}<.05,{ }^{*} * \mathrm{p}<.01, * * * \mathrm{p}<.001$

For a few examples, negative relationships between social expenditure and generalized trust were stronger in Central and Southern Asian countries compared to Estern Asian countries. In terms of the relationships between social expenditure and social networks, although directions of relationships were negative for countries in Estern, Central, and South-Eastern Asia, the opposite was true for Southern Asian countries. The difference in the magnitude of the relationships was statistically significant between Eastern Asian countries and Sourthern Asian countries. Interaction effects seemed to be strongest for social norms. For Estern, Central, and South-Eastern Asian countries, higher levels of social expenditure were associated with higher levels of social norms, and this relationship was strongest in South-Eastern Asian countries. However, the relationship turned to the opposite direction for Southern Asian countries.

\section{Discussion}

This study empirically explored the relationship between social policy and three forms of social capital based on both macro- and micro-level data from 24 Asian countries. Findings from aggregate-level bivariate regression suggested that there are no significant associations between social expenditure and two of three social capital 
measures, generalized trust and social networks. The relationship between social expenditure and social norms was found to be significant indicating that higher levels of social expenditure may lead to higher social norms. Multivariate regression analyses based on both micro- and macro-level datasets showed that the relationship between social expenditure and social capital varies depending on which kinds of social capital measures are used. Social expenditure did not seem to be related to generalized trust, but significant relationships were found for other two meausres of social capital although the directions of relationships were opposite. These findings clearly show that neither the crowding-in nor crowing-out hypothesis are fully supported, and empirical evidence is mixed depending on the forms of social capital at least for the sample of Asian countries. Further, analysis on the interaction effects between social expenditure and regional dummies suggested that the effect of social policy on social capital could substantially differ across sub-regions within Asian countries.

This study has important theoretical implications in that it adds empirical evidence to the current literature on the relationships between social policy and social capital based on the experiences of Asian countries. Given the contradictory predictions of two competing hypotheses and inconsistent evidence, more empirical research is needed especially for Asian countries to which not much attention has been paid. The findings from this study also have policy implications. Unlike the argument of the crowding-out hypothesis, social policy, in a broader term, welfare state, may not have detrimental effects on accumulating social capital, and even have positive effects on creating certain types of social capital. Policy-makers may have to keep in mind that social capital within the civil society and social policy in the public arena can be compatible each other and flourish together. Policy-makers need to seek for ways to strengthen and develop both social policy and social capital, and the findings presented in this study may help them take appropriate measures in these endeavors.

The crucial task goingforward is to further explore explantions why the relationship between social policy and social capital differs by forms of social capital and across sub-regions in Asian countries. For example, prior studies based on Western countries with advanced economies suggested that the design of welfare state insitutions matters for making or breaking social capital (e.g., van Oorschot \& Arts, 2005). However, those in-depth explanations might be hardly possible in the current study because theoretical and empirical work on welfare states, social capital, or the relationship between the two are quite limited. The very purpose of this study is to show varying relationships between social policy and social capital among Asian countries in a rather exploratory manner, and call for more research and discussion on this very important issue. More in-depth empirical and qualitative case studies need to be conducted in the future to understand complex relationships between social policy and social capital in Asian countries.

\section{Acknowledgments}

This work was supported by Incheon National University Research Grant in 2015.

\section{References}

Arts, W., Halman, L., \& van Oorschot, W. (2003). The welfare state: Villain or hero of the piece? In W. Arts, J. Hagenaars, \& L. Halman (Eds.), The cultural diversity of European unity (pp. 275-310). Leiden: Brill.

Bartel, K. P. R., Cozzi, G., \& Mantovan, N. (2011). Public spending and volunteering: "The Big Society", crowding out, and volunteering capital (MPRA Paper No. 29730).

Bourdieu, P. (1985). The forms of capital. In J. G. Richardson (Ed.), Handbook of Theory and Research for the Sociology of Education, (pp. 241-258). New York, NY: Greenwood Press.

Bredtmann, J. (2016). Does government spending crowd out voluntary labor and donations? (IZA World of Labor No. 299). https://doi.org//10.15185/izawol.299

Brewer, K., Oh, H., \& Sharma, S. (2014). "Crowing in" or "crowding out"? An examination of the impact of the welfare state on generalized social trust. International Journal of Social Welfare, 23, 61-68. https://doi.org//10.1111/ijsw.12019

Coleman, J. S. (1988). Social capital in the creation of human capital. American Journal of Sociology, 94, 95-120. https://doi.org/10.1086/228943

Compton, M. E. (2018). Less bang for your buck? How social capital constrain the effectiveness of social welfare spending. State Politics \& Policy Quarterly, 18(3), 215-245. https://doi.org//10.1177/1532440018775424

Ferragina, E. (2017). The welfare state and social capital in Europe: Reassessing a complex relationship. International Journal of Comparative Sociology, 58(1), 55-90. https://doi.org//10.1177/0020715216688934

Finsveen, E. M., \& van Oorschot, W. (2007, May). How does the welfare state affect social capital? A literature 
study (Paper presentation). ECPR Joint Session, Helsinki.

Fukuyama, F. (2000). Social capital and civil society (IMF Working Paper No. 00/74). Retrieved from International Monetary Fund website: https://www.imf.org/external/pubs/ft/wp/2000/wp0074.pdf

Hagfors, R., \& Kajanoja, J. (2007, March 29-31). The welfare state, inequality and social capital (Paper presentation). ESRC Social Contexts and Responses to Risk Network (SCARR) Conference, Queens' College, Cambridge.

Healy, T. (2002, September 25-27). The measurement of social capital at international level (Paper presentation). International Conference on the Measurement of Social Capital, London.

ILO (2017). World social protection report 2017-2019: Universal social protection to achieve the sustainable development goals. Geneva: Internatinal Labour Office.

Kaariainen, J., \& Lehtonen, H. (2006). The variety of social capital in welfare state regimes: A comparative study of 21 countries. European Societies, 8(1), 27-57. https://doi.org//10.1080/14616690500491399

Kumlin, S., \& Rothstein, B. (2005). Making and breaking social capital: The impact of welfare state institutions. Comparative Political Studies, 38(4), 339-365. https://doi.org/10.1177/0010414004273203

OECD (2001). The well-being of nations: The role of human and social capital. Centre for Educational Research and Innovation, Paris.

Putnam, R. D. (1995). Bowling alone: America's declining social capital. Journal of Democracy, 6, 65-78.

Putnam, R. D. (2000). Bowling alone: The collapse and revival of American community. New York; London: Simon \& Schuster.

Rostein, B., \& Uslander, E. (2005). All for one: Equality, corruption, and social trust. World Politics, 58, 41-72. https://doi.org//10.1353/wp.2006.0022

Scheepers, P., Grotenhuis, M. T., \& Gelissen, J. (2002). Welfare states and dimensioins of social capital: Cross-national comparisons of social contacts in European countries. European Societies, 4(2), 185-207. https://doi.org//10.1080/14616690220142781

Skocpol, T. (1996). Unravelling from above. The American Prospect, 25, 20-25.

Tamilina, L. (2009). The impact of welfare state development on social trust formation: An empirical investigation. Electronic Journal of Knowledge Management, 7(4), 501-508.

van Oorschot, W., \& Arts, W. (2005). The social capital of European welfare states: The crowding out hypothesis revisited. Journal of European Social Policy, 15(1), 5-26. https://doi.org//10.1177/0958928705049159

van Oorschot. W., \& Finsveen, E. (2010). Does welfare state reduce inequalities in people's social capital? International Journal of Sociology and Social Policy, 30(3/4), 182-193. https://doi.org//10.1108/01443331011033364

Visser, M., Gesthuizen, M., \& Scheepers, P. (2018). The crowding in hypothesis revisited: New insights into the impact of social protection expenditure on informal social capital. European Societies, 20(2), 257-280. https://doi.org//10.1080/14616696.2018.1442928

Wit, A. D., Neumayr, M., Handy, F., \& Wiepking, P. (2018). Do government expenditures shift private philanthropic donations to particular fields of welfare? Evidence from cross-country data. European Sociological Review, 34(1), 6-21. https://doi.org//10.1093/esr/jcx086.

Woolcock, M. M. (2001). The place of social capital in understanding social and economic outcomes, Isuma: Canadian Journal of Policy Research, 2(1), 11-17.

Wooldridge, J. M. (2002). Econometric analysis of cross section and panel data. Cambridge, MA: Massachusetts Institute of Technology.

\section{Copyrights}

Copyright for this article is retained by the author(s), with first publication rights granted to the journal.

This is an open-access article distributed under the terms and conditions of the Creative Commons Attribution license (http://creativecommons.org/licenses/by/4.0/). 